\title{
"Analysis of readmissions to the emergency department among patients presenting with abdominal pain"
}

Artur Kacprzyk ${ }^{1}$, Tomasz Stefura' ${ }^{1}$ Katarzyna Chłopaś ${ }^{1}$, Kaja Trzeciak , Aleksandra Załustowicz², Mateusz Rubinkiewicz ${ }^{2}$, Michał Pędziwiatr ${ }^{2,3}$, Kazimierz Rembiasz ${ }^{2}$ and Piotr Major ${ }^{2,3^{*}}$

\begin{abstract}
Background: Abdominal pain is one of the most common complaints among patients admitted to the Emergency Department (ED). Diagnosis and management of abdominal pain may be a challenge and there are patients who require admission to the ED more than once in a short period of time. Our purpose was to assess the incidence of readmissions among patients treated in the ED due to abdominal pain and to investigate the impact of readmission on the further course of treatment.

Methods: We conducted a prospective observational study, which included patients admitted to the ED in one academic, teaching hospital presenting with non-traumatic abdominal pain in a three-month period. Analyzed factors included demographic data, details related to first and subsequent visits in the ED and the course of hospitalization.
\end{abstract}

Results: Overall, 928 patients were included to the study and 101 (10.88\%) patients were admitted to the ED more than once during three-month period. Patients visiting ED repeatedly were older $(p=0.03)$ and more likely to be hospitalized $(p<0.01)$ compared to single-visit patients. Patients during their subsequent visits spent more time in the $\operatorname{ED}(p=0.01)$, had greater chance to repeat their appointment $(p=0.04)$, be admitted to the hospital $(p<0.01)$ and were more likely diagnosed with cholelithiasis $(p=0.03)$ compared to patients on their initial visit. If admitted to the surgical department they were also more often qualified for surgical procedure than patients on their first visit $(p<0.01)$. In a group of patients admitted to the surgical department there were no significant differences in rates of conversion, postoperative complications and mortality between subgroups.

Conclusions: Readmissions among patients presenting with abdominal pain are a common phenomenon with prevalence of $10.88 \%$. They are most commonly associated with cholelithiasis and occur more frequently among older patients, which suggests, that elderly require more attention during ED managements.

Keywords: Abdominal pain, Emergency department, Readmission

\footnotetext{
* Correspondence: piotr.major@uj.edu.pl

${ }^{2}$ 2nd Department of General Surgery, Jagiellonian University Medical College, Kopernika 21 St, 31-501 Cracow, Poland

${ }^{3}$ Centre for Research, Training and Innovation in Surgery (CERTAIN Surgery),

31-501 Cracow, Poland

Full list of author information is available at the end of the article
}

C C The Author(s). 2020 Open Access This article is licensed under a Creative Commons Attribution 4.0 International License, which permits use, sharing, adaptation, distribution and reproduction in any medium or format, as long as you give appropriate credit to the original author(s) and the source, provide a link to the Creative Commons licence, and indicate if changes were made. The images or other third party material in this article are included in the article's Creative Commons licence, unless indicated otherwise in a credit line to the material. If material is not included in the article's Creative Commons licence and your intended use is not permitted by statutory regulation or exceeds the permitted use, you will need to obtain permission directly from the copyright holder. To view a copy of this licence, visit http://creativecommons.org/licenses/by/4.0/. The Creative Commons Public Domain Dedication waiver (http://creativecommons.org/publicdomain/zero/1.0/) applies to the data made available in this article, unless otherwise stated in a credit line to the data. 


\section{Background}

Emergency Department (ED) is an essential component of healthcare system. Number of patients treated at ED has been rising constantly [1]. It is necessary to maintain the highest quality of care despite growing number of patients.

Management of patients presenting with pain or tenderness in the abdominal area at the ED is conducted by various physicians including general surgeons. It is often challenging and it may be linked to increased rate of readmissions [2, 3].

Misdiagnosis, delayed treatment and inappropriate discharge advice was reported to occur in $50 \%$ of readmission cases [4]. Incidence of readmission to ED in a short period of time may signify that the previous evaluation of patient's health status was inadequate [5]. Thus, frequent readmissions at EDs may be used as an indicator of low quality of care $[4,6]$. The readmitted patients may be associated with increased complications and mortality rates compared to a single-visit patients $[7,8]$. Moreover, often revisits generate higher costs than single-visit patients and contribute to overcrowding the ED [9].

Assessment of incidence and factors associated with readmissions of those patients may result in higher level of practitioners' awareness and improvement of healthcare at the EDs.

\section{Methods}

\section{Aim of the study}

Our purpose was to assess the incidence of readmissions among patients treated in the ED due to abdominal pain. We also aimed to investigate the influence of ED readmission on their further course of treatment.

\section{Setting}

The study was conducted at the ED of an academic center (tertiary referral level), which admits adult patients with illnesses or injuries requiring immediate medical attention. Patients are constantly supervised by at least 4 physicians working on call. Health benefits provided in this unit are preceded by medical segregation - TRIAGE system (confirmation or exclusion of an emergency health disorder and segregation of admitted patients based on the severity of their condition). TRIAGE is followed by full diagnostics and a necessary wide range of possible specialist consultations. The ED has access to a modern diagnostic imaging, equipment allowing for measurement of critical parameters and to a diagnostic laboratory with possibility of performing a full panel of tests. Treatment in the ED is conducted to the extent necessary for stabilizing the patient's condition. Patients admitted to the ED may be transferred to nearly 40 clinical departments of an academic center, with whom the ED is constantly cooperating.

\section{Study design}

We conducted a prospective observational study, which included patients admitted to the ED in one academic, teaching hospital presenting with non-traumatic abdominal pain in a three-month period (from January to March 2019). Inclusion criteria included presence of abdominal pain or abdominal tenderness during initial physical examination, age of 18 years old or higher, admission to the ED. Patients were selected by an ED physician who obtained necessary data with the use of computer software. The data was extracted at the end of the study period for further analysis. A 30-day follow-up period was additionally analyzed in order to assess the frequency of readmissions with highest possible precision. Study is designed and described regarding all STROBE checklist points for observational studies [10].

Patients were divided into two groups: patients who presented to the ED once and patients who presented more than once within a period of 30 days. Analyzed factors included age, sex, arrival and discharge time, length of stay in the ED, time since previous visit, additional tests taken in the ED (chest or abdomen radiograph, computed tomography (CT) scan, gastroscopy), ED discharge diagnosis, transfer to another department and in addition for those admitted to surgical ward: length of hospitalization, need and type of surgery, surgical complications rate, conversion rate, mortality and final diagnosis at the end of hospitalization. In analysis of subsequent visits to the ED we defined a readmission as a return of patient treated previously because of abdominal pain, reported again with the same or intensified symptoms within 30 days since previous discharge. Patients returning with other medical problem, not related to abdominal pain were excluded from group of patients with numerous visits. Additional tests were identified as diagnostic procedures not included in the standard protocol of care used in our ED including CT scan and gastroscopy.

\section{Analysis of endpoints}

The primary endpoint was to determine the incidence of 30-day readmissions to the ED and compare patients admitted to the ED once and patients readmitted to the ED in terms of:

- age

- sex

- rate of hospital admissions

- rate of surgical ward admissions

- rate of non-surgical ward admissions 
The secondary endpoint was to assess the differences between initial visit to the ED and every subsequent visit including:

- total time spent in the ED

- incidence of a subsequent visit

- number of performed additional tests

- proportion of patients admitted to the surgical ward

- proportion of patients qualified for surgery

- indications for surgical treatment

- conversions during surgery (from laparoscopy to laparotomy)

- postoperative complications

- mortality rate

- length of stay (LOS)

\section{Statistical analysis}

Statistical data were calculated using StatSoft STATISTICA version 13. Shapiro-Wilk test was used for evaluating the normality of data distribution. Results were presented as a mean with standard deviation (SD) or median and interquartile range (IQR) for non-normally distributed values. To compare non-normally distributed data a non-parametric Mann-Whitney U test was used. During testing categorical variables, the Chi-square test of independence was applied. Results were considered statistically significant when $p$ value was found to be $<0.05$.

\section{Ethics approval and consent to participate}

All procedures followed the ethical standards of the responsible committee on human experimentation (institutional and national) and 2013 Fortaleza revision of 1975 Declaration of Helsinki. Written informed consent was obtained from all participants.

\section{Results}

\section{Material}

In the 3-month study period, 11,306 patients were treated in the ED of our academic center. Among those, 928 patients met the study inclusion criteria (Fig. 1). Median age of the study group was 42 years (IQR: 2662). It included 571 (61.53\%) women and 357 (38.47\%) men. Overall, $698(75.22 \%)$ patients admitted to the ED were discharged home, 97 (10.45\%) patients were hospitalized in a surgical ward and $133(14.33 \%)$ were hospitalized in a non-surgical ward. The most frequent ED discharge diagnosis in whole group was "other or unidentified abdominal pain" in $52.59 \%$ of cases. In group admitted to surgical ward patients most often reported problems associated with biliary tract $(28,87 \%)$, acute appendicitis $(21,65 \%)$, obstruction $(13,41 \%)$ and gastrointestinal hemorrhage (11,34\%). Diagnosis classified as "other" (36,09\%), unidentified abdominal pain $(30,83 \%)$ and problems with biliary tract $(16,54 \%)$ dominated among patients relocated to non-invasive treatment wards. Table 1 presents ED discharge diagnosis for all presented groups. (Table 1.)

\section{Primary endpoints}

Overall, a group of $827(89.12 \%)$ patients presented to the ED only once and $101(10.88 \%)$ patients presented to the ED more than one time. A group of 23 (2.48\%) patients were admitted for the second time during $24 \mathrm{~h}$ since initial discharge, 30 (3.23\%) patients during $48 \mathrm{~h}, 39$ (4.20\%) patients during $72 \mathrm{~h}, 57(6.14 \%)$ patients in one week, 78 $(8.41 \%)$ patients in two weeks and $101(10.88 \%)$ in 30 days. Figure 2. shows distribution of patients depending on the time since initial discharge to the second admission to the ED. In comparison with a single-visit group, multiple-visit patients were significantly older $(p=0.03)$. The rates of males and females in both groups was comparable $(p=$

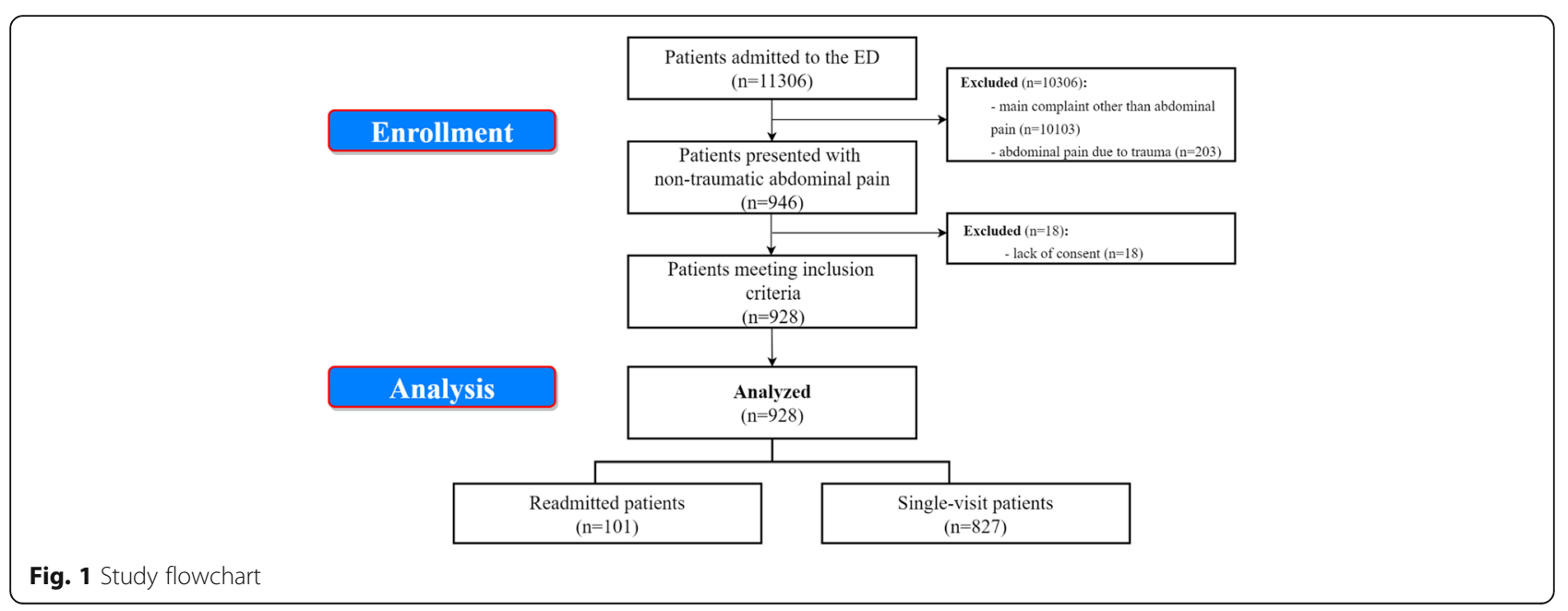


Table 1 Study group characteristics

\begin{tabular}{|c|c|c|c|c|}
\hline \multirow[t]{2}{*}{ VARIABLES } & \multirow{2}{*}{$\begin{array}{l}\text { ALL } \\
\text { PATIENTS } \\
\text { WITH } \\
\text { ABDOMINAL } \\
\text { PAIN } \\
\end{array}$} & \multirow{2}{*}{$\begin{array}{l}\text { PATIENTS } \\
\text { DISCHARGED } \\
\text { HOME AFTER } \\
\text { 1ST VISIT }\end{array}$} & \multicolumn{2}{|c|}{ PATIENTS REFERRED TO HOSPITAL } \\
\hline & & & SURGICAL WARD & $\begin{array}{l}\text { NON-INVASIVE } \\
\text { TREATMENT WARD }\end{array}$ \\
\hline n (\% of all) & $928(100.00)$ & $698(75.22)$ & $97(10.45)$ & $133(14.33)$ \\
\hline age - median (IQR) & $42(26-62)$ & $38(25-60)$ & $55(34-70)$ & $58(36-75)$ \\
\hline females - $n$ (\% of group) & $571(61.53)$ & $434(62.18)$ & $57(58.76)$ & $80(60.15)$ \\
\hline males - n (\% of group) & $357(38.47)$ & $264(37.82)$ & $40(41.24)$ & $53(39.85)$ \\
\hline \multicolumn{5}{|l|}{$\begin{array}{l}\text { ED discharge diagnosis - } n \\
\text { (\% of group) }\end{array}$} \\
\hline unidentified abdominal pain & $488(52.59)$ & $441(63.18)$ & $6(6.19)$ & $41(30.83)$ \\
\hline renal and urinary disease & $106(11.42)$ & $103(14.76)$ & $0(0.00)$ & $3(2.26)$ \\
\hline biliary tract related disease & $85(9.16)$ & $36(5.16)$ & $27(27.84)$ & $22(16.54)$ \\
\hline Gl tract bleeding & $24(2.59)$ & $6(0.86)$ & $11(11.34)$ & $7(5.26)$ \\
\hline acute appendicitis & $22(2.37)$ & 0 & $22(22.68)$ & $0(0.00)$ \\
\hline acute gastroenteritis & $20(2.16)$ & $19(2.72)$ & 0 & $1(0.75)$ \\
\hline acute intestinal obstruction & $14(1.51)$ & 0 & $14(14.43)$ & 0 \\
\hline peptic ulcer disease & $9(0.97)$ & $3(0.43)$ & $6(6.19)$ & 0 \\
\hline gynaecological disease & $6(0.65)$ & $3(0.43)$ & 0 & $3(2.26)$ \\
\hline neoplasm & $6(0.65)$ & $4(0.57)$ & 0 & $2(1.50)$ \\
\hline other & 148 (15.95) & 83 (11.89) & $11(11.34)$ & $54(40.60)$ \\
\hline
\end{tabular}

IQR - interquartile range; ED - Emergency Department; GI - gastrointenstinal

0.64). Patients admitted to the ED only once were less likely to be hospitalized than those who were admitted multiple times $(27.81 \%$ vs $44.55 \%, p<0.01)$. Among patients admitted to the ED once, 84 (10.45\%) were admitted to surgical ward and 126 (14.33\%) were admitted to the non-surgical ward. Remaining 617 (75.22\%) of patients were discharged from the hospital. In the group of patients admitted to the ED multiple times 36 (35.65\%) of them were not admitted to hospital, 40 (39.60\%) were admitted to surgical ward and 25 (24.75\%) were admitted to non-surgical ward. (Table 2).

\section{Secondary endpoints}

Patients during their subsequent visits spent more time in the ED than during their first visit [4 $\mathrm{h}$ (IQR: $3-6$ ) vs. $4.68 \mathrm{~h}$ (IQR: $3-7, p=0.01$ ]. They also had greater chance to repeat their appointment $[\mathrm{OR}=1.70$ (95\%CI: $1.02-$ 2.85), $p=0.04$ ] and greater chance of hospital admission $[\mathrm{OR}=1.82(95 \% \mathrm{CI}: 1.22-2.71, p<0.01)]$ compared to patients on their initial visit. Analysis revealed that patients admitted to surgical ward after their subsequent visit in the ED were more often qualified for surgical procedure than patients after their index visit $[\mathrm{OR}=2.46(95 \% \mathrm{CI}$ :

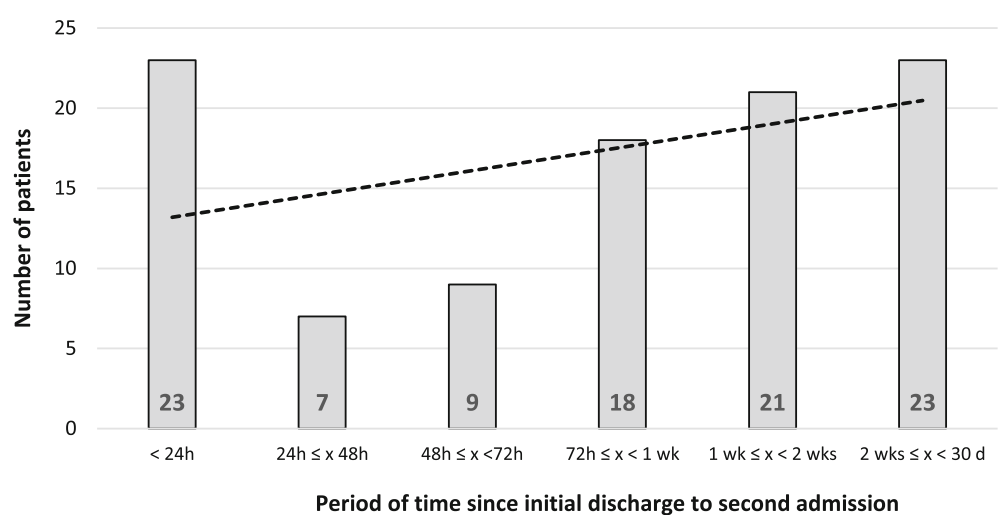

Fig. 2 Distribution of patients depending of the period of time between initial discharge to the second admission to the ED ( $h-$ hour, $d-d a y$, wk. - week) 
Table 2 Comparison of single- and multiple-admission patients (primary endpoints)

\begin{tabular}{|c|c|c|c|c|c|c|c|}
\hline & \multicolumn{4}{|c|}{ Admissions to the ED: } & \multirow[t]{3}{*}{$p$} & \multirow[t]{3}{*}{ OR } & \multirow[t]{3}{*}{$95 \% \mathrm{Cl}$} \\
\hline & \multicolumn{2}{|c|}{ Single admission patients } & \multicolumn{2}{|c|}{ Multiple admission patients } & & & \\
\hline & $n$ & $\%$ & $n$ & $\%$ & & & \\
\hline Number of patients & 827 & 89.12 & 101 & 10.88 & & & \\
\hline Age - years (IQR) & 42 & $(26-62)$ & 50 & $(32-65)$ & 0.0336 & & \\
\hline \multicolumn{8}{|l|}{ Sex } \\
\hline Females & 511 & 61.79 & 60 & 59.41 & 0.6430 & & \\
\hline Males & 316 & 38.21 & 41 & 40.59 & & & \\
\hline \multicolumn{8}{|l|}{ Number of visits } \\
\hline 1 & 827 & 100 & - & - & & & \\
\hline 2 & - & - & 85 & 84.16 & & & \\
\hline 3 & - & - & 12 & 11.88 & & & \\
\hline 4 & - & - & 3 & 2,97 & & & \\
\hline 5 & - & - & 1 & 0.99 & & & \\
\hline Patients admitted to hospital & 210 & 27.81 & 65 & 64.35 & $<0.001$ & 5.31 & $3.43-8.21$ \\
\hline Patients admitted to surgical ward & 84 & 10.45 & 40 & 39.60 & 0.0027 & 2.40 & $1.36-4.25$ \\
\hline $\begin{array}{l}\text { Patients admitted to } \\
\text { non-invasive treatment ward }\end{array}$ & 126 & 14.33 & 25 & 24.75 & 0.0156 & 1.83 & $1.12-2.99$ \\
\hline
\end{tabular}

ED - Emergency Department; IQR - interquartile range

$1.40-4.32), p<0.01]$. In group of patients admitted to a surgical department, those after a single ED admission were most like to be qualified for surgery due to appendicitis (32.79\%) followed by cholelithiasis/gallstones (18.03\%). Patients admitted to surgical department after a multiple ED admissions were most likely to be qualified for invasive procedure due to cholelithiasis (44.44\%) followed by appendicitis (16.67\%). They were also characterized by longer LOS compared to patients admitted after index ED visit [median time (days): 3 (2-5) vs. 4 (3-6), $p=0.04]$. There were no significant differences in rates of conversion $(p=0.78)$, postoperative complications $(p=0.82)$ and mortality $(p=0.96)$ between those two groups. (Table 3.).

\section{Discussion}

Abdominal pain seems to be one of the most important medical problems associated with high risk of readmissions to the ED [11]. In our study approximately one of every ten patients presenting with abdominal pain was readmitted to the ED during 30 days after initial visit. Depending on a study design ED readmission rate varied from $0.39 \%$ to even $49.3 \%$, which resulted mainly from different readmission time frames (range $48 \mathrm{~h}$ to 365 days) and characteristics of the study group [11, 12]. We found two studies investigating readmissions after 30 days since initial visit: Patterson et al. estimated it as $12.4 \%$ among patients with abdominal pain and Friedman et al. assessed it as $12 \%$ among older adults [13, 14] In Meltzer's study focused on patients with abdominal pain and 365-day readmission rate was $41 \%$ [12]. Our revisit rates of 2.48, $4.14,6.20 \%$ in consecutive time frames of $48 \mathrm{~h}, 72 \mathrm{~h}$ and one week are consistent with previous findings [15].

Patients with more than one visit at the ED were significantly older than single-visit patients, which was also proved in previous publications [14, 16-20]. In the study by $\mathrm{Hu}$ et al. old age was identified as an independent risk factor, not deriving from higher incidence of comorbidities [17]. Gabayan et al. described predictors of readmission in adults such as older age, skilled nursing facility use, leaving the ED against medical advice and chronic conditions such as renal disease and heart failure [21]. In our study group majority of readmitted patients were subsequently admitted to a surgical ward. It is associated with most common diseases diagnosed among those patients, which were appendicitis and biliary tract diseases - ailments that are often misdiagnosed and recurring [22-24].

Previous studies present abdominal pain as a one of the most often symptoms observed in readmitted patients with prevalence ranging from 15.5 to $29.1 \%$, as well as the most common complaint leading people to the EDs $[4,8,16,25,26]$. In our study the most common discharge diagnosis after readmission to the ED visit was cholelithiasis. Furthermore, cholelithiasis was observed significantly more often in patients during their subsequent admission to the ED. It may be explained by recurrent symptoms, which are often observed by patients who have recently experience biliary colic symptoms [27]. Williams et al. showed that failure to achieve a timely surgical follow-up in this group of patients may result in 
Table 3 Comparison of initial visit and readmission to the ED (secondary endpoints)

\begin{tabular}{|c|c|c|c|c|c|c|c|}
\hline \multirow[b]{2}{*}{ No of visits - $\mathrm{n}$ (\% of all visits) } & \multicolumn{2}{|c|}{ Initial visit } & \multicolumn{2}{|c|}{ Readmission } & \multirow[t]{2}{*}{ p } & \multirow[t]{2}{*}{ OR } & \multirow[t]{2}{*}{$95 \% \mathrm{Cl}$} \\
\hline & 928 & $88.38 \%$ & 122 & $11.62 \%$ & & & \\
\hline Total time spent on the ED - hours (IQR) & 4 & $(2.75-6.04)$ & 4.68 & $(3.48-6.98)$ & 0.0054 & & \\
\hline Not the last visit - $\mathrm{n}$ repeated visits (\% of visits) & 101 & $10.88 \%$ & 21 & $17.21 \%$ & 0.0422 & 1.7 & $1.02-2.85$ \\
\hline \multicolumn{8}{|l|}{ Number of additional imaging tests - $n$ (\% of visits) } \\
\hline 0 & 889 & $95.80 \%$ & 115 & $94.26 \%$ & & & \\
\hline 1 & 39 & $4.20 \%$ & 6 & $4.92 \%$ & 0.6897 & & \\
\hline 2 & 0 & $0 \%$ & 1 & $0.82 \%$ & & & \\
\hline Admission to hospital ward $-n$ (\% of visits) & 230 & $24.78 \%$ & 47 & $38.52 \%$ & 0.0014 & 1.90 & $1.28-2.82$ \\
\hline Admission to surgical ward - $n$ (\% of visits) & 97 & $10.45 \%$ & 29 & $23.77 \%$ & $<0.001$ & 2.67 & $1.67-4.26$ \\
\hline Qualification for invasive surgical treatment - $\mathrm{n}$ (\% of group) & 61 & $6.57 \%$ & 18 & $16.83 \%$ & 0.0017 & 2.46 & $1.40-4.32$ \\
\hline \multicolumn{8}{|l|}{ Indication } \\
\hline Cholelithiasis/gallstones & 11 & $18.03 \%$ & 8 & $44.44 \%$ & 0.0259 & 3.64 & $1.17-11.32$ \\
\hline Appendicitis & 20 & $32.79 \%$ & 3 & $16.67 \%$ & 0.1859 & 0.41 & $0.11-1.58$ \\
\hline Hernia & 8 & $13.11 \%$ & 0 & $0.00 \%$ & 0.2314 & 0.17 & $0.01-3.09$ \\
\hline Acute pancreatitis & 7 & $11.48 \%$ & 1 & $5.56 \%$ & 0.5740 & 0.53 & $0.06-4.68$ \\
\hline Obstruction & 4 & $6.56 \%$ & 1 & $5.56 \%$ & 0.8782 & 0.83 & $0.09-8.01$ \\
\hline Neoplasm & 3 & $4.92 \%$ & 1 & $5.56 \%$ & 0.9137 & 1.13 & $0.11-11.65$ \\
\hline Peptic ulcer & 3 & $4.92 \%$ & 0 & $0.00 \%$ & 0.6047 & 0.45 & $0.02-9.15$ \\
\hline Other & 5 & $8.20 \%$ & 4 & $22.22 \%$ & 0.1132 & 3.20 & $0.76-13.50$ \\
\hline Conversion - $\mathrm{n}$ (\% of group) & 2 & $3.28 \%$ & 0 & $0.00 \%$ & 0.7789 & 0.64 & $0.03-14.01$ \\
\hline Postoperative complications - $n$ ( $\%$ of group) & 8 & $13.11 \%$ & 2 & $11.10 \%$ & 0.8225 & 0.82 & $0.16-4.30$ \\
\hline Death - n (\% of group) & 1 & $1.03 \%$ & 0 & $0.00 \%$ & 0.9584 & 1.09 & $0.04-27.91$ \\
\hline Length of hospital stay - days (IQR) & 3 & $(2-5)$ & 4 & $(3-6)$ & 0.0443 & & \\
\hline
\end{tabular}

ED - Emergency Department; IQR - interquartile range

multiple ED readmissions and emergent gallstone-related hospitalizations [28]. Appendicitis, which was the second most common final diagnosis during subsequent visits was the reason for readmission of three patients. Delayed diagnosis was associated with significantly higher rate of hospital-admissions, more frequent need of invasive treatment and longer LOS. Postoperative complication rates were comparable in both groups.

Imaging techniques have been more frequently used in management of patients with abdominal pain, however have brought minor advantages in diagnostic specificity $[26,29,30]$. Medford-Davis et al. presented high incidence of diagnostic errors reaching $35 \%$ in high risk patients with abdominal pain, involving most commonly history taking, but also ordering insufficient tests and problems with follow-up of abnormal test results [31]. Nonetheless, Patterson et al. proved effectiveness of CT imaging in reduction of 30-day revisit rate of patients with non-traumatic abdominal pain [14]. The number of performed imaging examinations did not differ between initial and subsequent admissions and did not influence the chance of readmission.
Subsequent admissions lasted significantly longer compared to the initial ones, which may contribute to increased overcrowding of EDs [32]. Cheng et al. suggested that initial visits may be shorter because ED doctors want to prevent overcrowding and patients do not wish to stay in observational room after achieving the relief of symptoms after initial treatment [33]. Therefore, the premature discharge may be related to inadequate treatment and be partially responsible for readmissions.

Our study is associated with several limitations. It is a prospective observational study based on ED and surgical department medical records. The study was carried out in only one center and the results may not be generalized to other setting, as the impact of demographic factors cannot be assessed. Furthermore, some of the patients may have been admitted to another ED after being admitted in our department. However, we believe that the rate of crossover cases is low and randomly distributed among groups. Further research needs to be conducted on larger group of patients and preferably include multiple centers located in close proximity to prevent the crossover bias. 


\section{Conclusion}

Readmissions among patients presenting with abdominal pain are a common phenomenon with prevalence of $10.88 \%$. Readmitted patients spend more time in the ED and are more often admitted to the hospital. They are also more likely to be qualified for invasive surgical treatment with comparable outcomes as a single-visit patients, except for a longer LOS. Readmissions are most commonly associated with cholelithiasis and occur more often among older patients, which suggests that elderly require more attention during ED hospitalization.

\section{Abbreviations}

ED: Emergency Department; LOS: Length of stay; CT: Computed tomography

\section{Acknowledgements}

Not applicable.

\section{Authors' contributions}

AK - designed and directed the project, interpretated the data, prepared the manuscript; TS - performed the calculations, interpreted the data, prepared manuscript, revised manuscript; $\mathrm{KC}, \mathrm{KT}$, - prepared the data, interpreted the data; $A Z, M R, M P, K R$ - contributed to the design and implementation of the research; PM - supervised the project, conceived the original idea, revised manuscript. All authors provided critical feedback and helped shape the research, analysis and manuscript. The author(s) read and approved the final manuscript.

\section{Funding}

The authors declare no funding.

\section{Availability of data and materials}

Data are available from the authors upon reasonable request

\section{Ethics approval and consent to participate}

All procedures followed the ethical standards of the responsible committee on human experimentation (institutional and national) and 2013 Fortaleza revision of 1975 Declaration of Helsinki. Written informed consent was obtained from all participants.

\section{Consent for publication}

Not applicable.

\section{Competing interests}

The authors declare no competing interests.

\section{Author details}

'Jagiellonian University Medical College, 31-008 Cracow, Poland. ${ }^{2}$ 2nd Department of General Surgery, Jagiellonian University Medical College, Kopernika 21 St, 31-501 Cracow, Poland. ${ }^{3}$ Centre for Research, Training and Innovation in Surgery (CERTAIN Surgery), 31-501 Cracow, Poland.

Received: 27 February 2020 Accepted: 5 May 2020

Published online: 12 May 2020

\section{References}

1. Statystyczny GU. Notatka informacyjna w oparciu o dane pozyskane w ramach statystyki publicznej. 2015;1-8.

2. Alvarado A How to improve the clinical diagnosis of acute appendicitis in resource limited settings. World J Emerg Surg [internet]. 2016;11:16. Available from: https://doi.org/https://doi.org/10.1186/s13017-016-0071-8.

3. Lauwers R, Van De Winkel N, Vanderbruggen N, Hubloue I. Munchausen syndrome in the emergency department mostly difficult, sometimes easy to diagnose: a case report and review of the literature. World J Emerg Surg [internet]. 2009;4:38. Available from: https://doi.org/https://doi.org/10.1186/ 1749-7922-4-38

4 Sri-on J, Nithimathachoke A, Tirrell GP, Surawongwattana S, Liu SW Revisits within 48 Hours to a Thai Emergency Department. Emerg Med Int [Internet].
2016;2016:1-5. Available from: http://www.hindawi.com/journals/emi/2016/ 8983573/.

5. Wu CL, Wang FT, Chiang YC, Chiu YF, Lin TG, Fu LF, et al. Unplanned Emergency Department Revisits within 72 Hours to a Secondary Teaching Referral Hospital in Taiwan. J Emerg Med. Elsevier Inc.; 2010;38:512-7.

6. Easter JS, Bachur R. Physicians' assessment of pediatric returns to the emergency department. J Emerg med [internet]. Elsevier Ltd; 2013;44:682688. Available from: http://dx.doi.org/https://doi.org/10.1016/j.jemermed. 2012.05.011.

7. Safwenberg $U$, Terént A, Lind L. Increased long-term mortality in patients with repeated visits to the emergency department. Eur J Emerg Med. 2010; 17:274-9.

8. Imsuwan I Characteristics of unscheduled emergency department return visit patients within 48 hours in Thammasat University Hospital. J Med Assoc Thai. 2011;94 Suppl 7

9. Baer RB, Pasternack JS, Zwemer FL. Recently discharged inpatients as a source of emergency department overcrowding. Acad Emerg Med. 2001;8:1091-4.

10. von Elm E, Altman DG, Egger M, Pocock SJ, Gøtzsche PC, Vandenbroucke $J P$. The strengthening the reporting of observational studies in epidemiology (STROBE) statement: guidelines for reporting observational studies. Ann Intern Med. 2007;147:573-8.

11. Trivedy CR, Cooke MW. Unscheduled return visits (URV) in adults to the emergency department (ED): a rapid evidence assessment policy review. Emerg med J [internet]. 2013:1-6 Available from: http://www.ncbi.nlm.nih. gov/pubmed/24165201.

12. Meltzer AC, Bregman B, Blanchard J. Depression is associated with repeat emergency department visits in patients with non-specific abdominal pain. West J Emerg Med. 2013;26:217-20.

13. Friedmann PD, Jin L, Karrison TG, Hayley DC, Mulliken R, Walter J, et al. Early revisit, hospitalization, or death among older persons discharged from the ED. Am J Emerg Med. 2001;19:125-9.

14. Patterson BW, Venkatesh AK, Alkhawam L, Pang PS. Abdominal computed tomography utilization and 30-day Revisitation in emergency department patients presenting with abdominal pain. Acad Emerg Med. 2015;22:803-10.

15. Han CY, Chen LC, Barnard A, Lin CC, Hsiao YC, Liu HE, et al. Early revisit to the emergency department: an integrative review. J Emerg Nurs [internet] Emergency Nurses Association; 2015;41:285-295. Available from: http://dx. doi.org/https://doi.org/10.1016/j.jen.2014.11.013.

16. White D, Kaplan L, Eddy L. Characteristics of patients who return to the emergency department within 72 hours in one community hospital. Adv Emerg Nurs J. 2011;33:344-53.

17. Hu SC. Analysis of patient revisits to the emergency department. Am J Emerg Med. 1992;10:366-70.

18. Abualenain J, Frohna WJ, Smith M, Pipkin M, Webb C, Milzman D, et al. The prevalence of quality issues and adverse outcomes among 72-hour return admissions in the emergency department. J Emerg med [internet]. Elsevier Ltd; 2013;45:281-288. Available from: http://dx.doi.org/https://doi.org/10. 1016/j.jemermed.2012.11.012.

19. Martin-Gill C, Reiser RC. Risk factors for 72-hour admission to the ED. Am J Emerg Med. 2004:22:448-53.

20. McCusker J, Healey E, Bellavance F, Connolly B. Predictors of repeat emergency department visits by elders. Acad Emerg Med. 1997:4:581-8.

21. Gabayan GZ, Asch SM, Hsia RY, Zingmond D, Liang $\sqcup$, Han W, et al. Factors associated with short-term bounce-back admissions after emergency department discharge. Ann Emerg Med [Internet]. Elsevier Inc.; 2013;62:136144.e1. Available from: http://dx.doi.org/https://doi.org/10.1016/j. annemergmed.2013.01.017

22. Ransohoff DF, Gracie WA. Treatment of gallstones. Ann Intern Med [internet]. 1993;1 19:606-619. Available from: https://doi.org/https://doi.org/ 10.7326/0003-4819-119-7_Part_1-199310010-00010.

23. Sosner E, Patlas MN, Chernyak V, Dachman AH, Katz DS. Missed Acute Appendicitis on Multidetector Computed Tomography and Magnetic Resonance Imaging: Legal Ramifications, Challenges, and Avoidance Strategies. Curr Probl Diagn Radiol [Internet]. 2017;46:360-4. Available from: http://www.sciencedirect.com/science/article/pii/S0363018817300683.

24. Sartelli M, Baiocchi GL, Di Saverio S, Ferrara F, Labricciosa FM, Ansaloni L, et al. Prospective Observational Study on acute Appendicitis Worldwide (POSAW). World J Emerg Surg. England. 2018;13:19.

25. Liaw SJ, Bullard MJ, Hu PM, Chen JC, Liao HC. Rates and causes of emergency department revisits within 72 hours. J Formos Med Assoc 
[Internet]. 1999;98:422-5. Available from: http://www.ncbi.nlm.nih.gov/ entrez/query.fcgi?cmd=Retrieve\&db=PubMed\&dopt=Citation\&list_uids= 10443066.

26. Hastings RS, Powers RD. Abdominal pain in the ED: A 35 year retrospective. Am J Emerg Med [Internet]. Elsevier Inc.; 2011;29:711-6. Available from: https://doi.org/10.1016/j.ajem.2010.01.045

27. Diehl AK, Sugarek NJ, Todd KH. Clinical evaluation for gallstone disease: usefulness of symptoms and signs in diagnosis. Am J Med. 1990;89:29-33.

28. Williams TP, Dimou FM, Adhikari D, Kimbrough TD, Riall TS. Hospital readmission after emergency room visit for cholelithiasis. I Surg Res [internet]. Elsevier Inc; 2015;197:318-323. Available from: http://dx.doi.org/ https://doi.org/10.1016/j.jss.2015.04.032.

29. Flum DR, Morris A, Koepsell T, Dellinger EP. Has misdiagnosis of appendicitis decreased over time? A population-based analysis. JAMA. 2001;286:1748-53.

30. Exadaktylos AK, Sadowski-Cron C, Mäder P, Weissmann M, Dinkel HP, Negri $M$, et al. Decision making in patients with acute abdominal pain at a university and at a rural hospital: does the value of abdominal sonography differ?. World J Emerg Surg [internet]. 2008;3:29. Available from: https://doi. org/https://doi.org/10.1186/1749-7922-3-29.

31. Medford-Davis L, Park E, Shlamovitz G, Suliburk J, Meyer AND, Singh H. Diagnostic errors related to acute abdominal pain in the emergency department. Emerg Med J. 2016:33:253-9.

32. Barzegari H, Fahimi MA, Dehghanian S. Emergency Department Readmission Rate within 72 Hours after Discharge; a Letter to Editor. Emerg (Tehran, Iran). 2017;5:e64

33. Cheng SY, Wang HT, Lee CW, Tsai TC, Hung CW, Wu KH. The characteristics and prognostic predictors of unplanned hospital admission within 72 hours after ED discharge. Am J Emerg Med [Internet]. Elsevier Inc;; 2013;31:1490-4. Available from: http://dx.doi.org/https://doi.org/10.1016/j.ajem.2013.08.004.

\section{Publisher's Note}

Springer Nature remains neutral with regard to jurisdictional claims in published maps and institutional affiliations.

Ready to submit your research? Choose BMC and benefit from:

- fast, convenient online submission

- thorough peer review by experienced researchers in your field

- rapid publication on acceptance

- support for research data, including large and complex data types

- gold Open Access which fosters wider collaboration and increased citations

- maximum visibility for your research: over $100 \mathrm{M}$ website views per year

At $\mathrm{BMC}$, research is always in progress.

Learn more biomedcentral.com/submissions 